\title{
NATALIDADE E EDUCAÇÃO
}

Écio Elvis Pisetta 1 .

“'Para que houvesse um inicio, o homem foi criado, sem que antes dele ninguém o fosse', diz Agostinho em sua filosofia política. Trata-se de um início que difere do início do mundo, pois não éo início de algo, mas de alguém que é, ele próprio, um iniciador" (ARENDT, 2014, p.222).

\section{INTRODUÇÃO: A QUESTÃO PELA EDUCAÇÃO.}

De que maneira investigamos a cada vez a educação? Quando a questionamos, qual o alcance de nossa corriqueira crítica? Assim, como compreendemos em geral a educação? E ainda podemos perguntar: para quem a educação é de fato uma questão, isto é, algo que mereça ser investigado e conhecido a partir e devido à sua essência? Esta última pergunta possui sentido radicalmente diferente das anteriores. Todas demonstram interesse pela educação. A última demanda atitude intelectual de acolhimento das vicissitudes próprias de tudo que é essencial. Será que a educação pode fazer alguma coisa conosco? É evidente. Mas de que maneira? Essa pergunta assume relevância se desejamos distinguir o interesse que a suscita daquele mais especializado e extremamente útil que, em geral, domina legitimamente as discussões.

A educação é tema amplo, envolvendo diversos pontos de vista. $\mathrm{O}$ que segue toma como ponto de partida algumas ideias retiradas do texto A crise na educação da pensadora política e filósofa $\mathrm{H}$. Arendt, A autora nos fornece certas provocações que acatamos em alguma medida, sem sermos fiéis em demasia à organização interna do texto base. Almejamos, assim, um olhar que problematize o fenômeno educacional de modo distinto daquele realizado no interior das especialidades da ciência da educação. A autora reivindica um olhar acerca da educação que não pode e não deve ser propriedade exclusiva dos profissionais especializados. Do mesmo modo, o pensamento acerca da educação não se confunde com a dedicação a um tema isolado em meio a tantos outros e restrito a algum país. Ali repercute fenômeno de totalidade: a vida humana no mundo, marcadamente, a existência política. "Pode-se admitir como uma regra geral neste século que qualquer coisa que seja possível em um país pode, em futuro previsível, ser igualmente possível em praticamente qualquer outro país" (ARENDT, 2007, p.222).

No interesse de deixarmo-nos atingir pelas propostas de H. Arendt organizamos nossa reflexão na ordem seguinte: iniciaremos dando uma resposta mínima (a) para o que a autora

\footnotetext{
1 Professor da Faculdade de Filosofia da Universidade Federal do Estado do Rio de Janeiro - UNIRIO. eciopisetta@gmail.com, http://orcid.org/0000-0002-1735-6893
} 
compreende por essência da educação, o fenômeno da natalidade; a partir destas ideias (b) faremos pequena incursão sobre a influência da filosofia pragmatista na educação que, no Brasil, tem em Anísio Teixeira seu maior expoente; por fim, teceremos (c) análise filosófica sobre o alcance desta compreensão para a educação. Com isso frisaremos a atualidade das observações da autora para nosso tempo.

\section{CONTEXTUALIZAÇÃO DA QUESTÃO PELA NATALIDADE.}

Por certo, a educação é algo de fundamental e decisivo para a sociedade em geral, de tal forma que a família atual já não pode mais esperar exclusivamente de si mesma a realização desta demanda. A sociedade necessita de instituições adequadas tanto para suprir aspectos profissionais requeridos pelo desenvolvimento científico e industrial quanto os que dizem respeito à estrutura espiritual de nosso tempo, presente nas compreensões de humanidade, pluralidade, liberdade, democracia (Cf. TEIXEIRA, 2007, p. 40-49). Vemos o Estado dispensando imensos esforços em algum projeto educacional. Mas as preocupações com a educação aparecem na sociedade em geral, nas políticas públicas, no posicionamento das nações umas frente às outras segundo as necessidades planificadas da atualidade. O ponto de vista levado a cabo por H. Arendt distingue-se desse oferecendo um interesse que antecede ou ultrapassa todo este viés prático e/ou utilitário. Pois este fenômeno remete para algo de outro, para algo que expõe e intensifica a totalidade da relação entre ser humano e mundo. A tensão e os conflitos característicos do esforço em prol da educação são deslocados de seus fins sempre restritos a este ou aquele país, a esta ou aquela prática política, a esta ou aquela corrente pedagógica ou tendência de interpretação da educação, a este ou aquele ideal que a justifica enquanto teoria formativa, para algo denominado de essência da educação, $a$ natalidade.

O porquê deste deslocamento pode ser explicado de algumas formas: a conquista de um ponto de vista não especializado capaz de agregar as discussões acerca da educação e, nesse sentido, revitalizá-las; um retorno à problematização da educação, atitude obscurecida pelas discussões pontuais realizadas no seio das especializações dominadas em geral pelo viés técnico; a necessidade teórica de, na contramão das tendências sociais modernas e contemporâneas, valorizar âmbitos distintos e conflitantes tais como o espaço privado versus o espaço público, o escola e a criança versus a sociedade em geral e o mundo adulto. A insistência na importância destes espaços legítimos e conflitantes chama nossa atenção para a contínua diluição dos mesmos na totalidade planificada e unidimensional de nosso tempo. Vivemos a época em que se constata certa indecência na demanda por singularidade e diferenciação, por mais que o discurso corriqueiro o endosse. 
A princípio, é evidente a constatação do fenômeno da natalidade como a essência da educação. A educação lida com crianças e jovens. Mas pode-se, segundo a autora, lidar com os novos de uma maneira que não leve suficientemente em conta o fenômeno do nascimento. Isto ocorre, por exemplo, quando concebemos as escolas como aquele lugar onde estão sendo preparados os profissionais do amanhã ou quando, em oposição a esta perspectiva, delegamos aos jovens a autonomia de gerenciar seu próprio crescimento intervindo o mínimo possível nos processos de aprendizagem. Num caso, a vida adulta é repetida na escola e orienta sua formação. Noutro caso, a separação/oposição na vida da criança das responsabilidades próprias do mundo adulto produz algo de danoso, já que pertence ao mundo a convivência entre adultos e jovens. Antecipar a vida adulta para a criança ou estender a infância o máximo possível para dentro da vida adulta não atendem suficientemente ao princípio da natalidade. Nesta investigação está em jogo uma reflexão que se distingue fundamentalmente da pergunta "por que Joãozinho não sabe ler" (ARENDT, 2007, p.222). Saber ou não saber ler e por que não se aprendeu a ler na idade adequada, por que existem tantos analfabetos, funcionais ou não, ou por que são ministrados determinados conteúdos programáticos em detrimento de outros, são questões relevantes que pertencem ao escopo das especializações pedagógicas.

A associação entre natalidade e educação não se esgota na constatação de que a educação se ocupa da formação e preparação das crianças, desde tenra idade, até a idade adulta, inserindo-as na sociedade e no mercado de trabalho. Não excluímos a conexão fatual da educação à preparação da criança e do jovem e de que esta formação é experimentada como um nascimento para a sociedade, que a função dos mestres corresponde de certa forma a uma arte de formar, informar e conduzir ou guiar os novos neste processo. O que se busca com a investigação acerca da essência da educação é a apresentação do sentido primário e subjacente de toda educação que se compromete com o fato de as crianças nascerem para o mundo onde já estão previamente convivendo seres humanos. O termo "mundo" em H. Arendt é conceito prévio (ou ontológico) não expressando nunca qualquer conjunto de coisas já dadas, mas apontando para uma dinâmica fundamental de constituição da existência humana. Como tudo que é essencial, "mundo" expressa a realidade da convivência como um contínuo e perigoso espaço que, diferentemente do da criança, não está em desenvolvimento para um estágio de maturidade mais elevado, mas em contínuo devir. A convivência mundana não está pronta e acabada, não está dada. Assim, "mundo" indica aquele espaço comum, público, corresponsável, de igualdade e diferenciação. Mundo e natalidade se alimentam mutuamente. $\mathrm{O}$ fato das crianças nascerem para o mundo não significa que o mundo já esteja fixado cabendo à educação a tarefa de enquadrar os jovens. Neste nascimento para o mundo reside a preocupação fundamental 
de renovação do próprio mundo comum, não no sentido de meramente substituir seus membros, como numa troca de parafusos, mas antes no sentido de uma convocação ao compromisso e à responsabilização com o que há de mais elevado na convivência entre iguais que são também diferentes. Os seres humanos não são animais ou robôs.

\section{O FENÔMENO DA NATALIDADE.}

Assim, segundo a autora, que significa "nascimento"? Que significa o fato filosóficopolítico de que seres nascem para o mundo? Interpretaremos algumas ideias extraídas do livro $A$ condição Humana no capítulo em que $\mathrm{H}$. Arendt disserta sobre a revelação do agente no discurso $e$ na ação (Cf. ARENDT, 2014, p. 219 ss).

A convivência humana torna plástica a historicidade da existência. Convivendo, os seres humanos compreendem em algum grau aqueles que já morreram, os que estão presentes e, também, os que virão, segundo as possibilidades racionais da "espécie", como algo comum e geral. Mas, para isso, necessitam também de capacidade que não se explica como pura generalidade: o discurso e a ação. Assim cada um se faz compreender em meio aos demais. Pois compreender e fazer-se compreender apontam para lados distintos da convivência. Com isso mostra-se algo de fundamental: os seres humanos vivem "o duplo aspecto da igualdade e da distinção" (ARENDT, 2014, p.219). Por meio da primeira convivem, partilham uma memória, necessidades, projetos, enfim, um mundo comum. Por meio da segunda e servindo-se do discurso e da ação, se revelam em sua singularidade diante dos demais como, por exemplo, apresentando aos demais determinada interpretação do passado ou determinado planejamento do futuro para fundamentar alguma tomada de decisão. Um aspecto não elimina o outro. No entanto, tocam regiões hierarquicamente distintas da convivência. Quem não fala ou não age, em termos de convivência, se oculta ou priva-se do aspecto da distinção frente aos demais. Ele não se torna "alguém" perante os outros porque, de certa forma, não se expõe. Expondo-se, o indivíduo afirma seu caráter único e insubstituível. Expondo-se realiza ou assume, frente aos demais, aquele nascimento há muito adiado.

Por certo, há de se perguntar acerca do sentido do discurso e da ação no contexto de pensamento da autora. Ora, todo discurso meramente compreensivo, travando diálogo entre “iguais", não colabora para que o agente se mostre e se deixe ver em sua singularidade e/ou

distinção. É que na mera compreensão estamos às voltas com o fato de sermos humanos sem termos sido atingidos, por assim dizer, pela peculiaridade deste acontecimento. Como nos recorda a autora, trata-se de uma "paradoxal pluralidade de seres únicos" (ARENDT, 2014, p.220). Estes seres 
únicos, por atos e palavras, mostram-se como agentes, apresentam-se se distinguindo por meio de ações e nas palavras. Enquanto ideal, valem mais as palavras e os atos dotados de grandiosidade, portanto incomuns, que não estão na boca e nas mãos de toda gente. E que, devido a esta grandiosidade, podem ser percebidos e admirados, estimulando sua repetição a exemplo de um modelo a ser seguido. Podemos lembrar o papel da obra homérica para a formação do homem grego clássico. Mesmo no seio da sociedade massificada mora em estado embrionário o desejo mais íntimo pela singularização. Se, por um lado, somos como todos o são, por outro, ninguém o quer ser, isto é, cada um quer ser como somente ele pode ser. E este acontecimento vem à luz na palavra e na ação frente aos outros. Isto não significa que a distinção seja fenômeno facilmente acatado. Ao contrário. É sempre espaço de conflitos. No entanto, tal iniciativa não se confunde com aquela mais genérica em que pleiteamos alguma coisa, como a satisfação de alguma necessidade ou a busca de algum ideal profissional já projetado na sociedade. Por meio da iniciativa presente no discurso e na ação alguém revela sua identidade e se afirma em algum grau como ser singular, o que sempre atrai o olhar perigoso do entorno.

“(...) "trata-se de uma iniciativa da qual nenhum ser humano pode abster-se sem deixar de ser humano" (ARENDT, 2014, p.220), porque deixaria "de ser uma vida humana, uma vez que já não é vivida entre os homens" (ARENDT, 2014, p.221).

"Mas a criança só é nova em relação a um mundo que existia antes dela, que continuará após sua morte e no qual transcorrerá sua vida. Se a criança não fosse um recém-chegado nesse mundo humano, porém simplesmente uma criatura viva ainda não concluída, a educação seria apenas uma função da vida e não teria que consistir em nada além da preocupação para com a preservação da vida e do treinamento e na prática do viver que todos os animais assumem em relação a seus filhos" (ARENDT, 2007, p. 235).

Os seres humanos são iniciadores à medida que assumem a tarefa de nascer para o mundo. Comprometem-se com o mundo comum de alguma maneira, afirmando, defendendo, interpretando, propondo, negando, convencendo, fazendo algo no âmbito do espaço da convivência de seres que são iguais e diferentes e não apenas executando atividades restritas à manutenção da espécie. Tratase da consciência de que não se está num mundo já pronto como o é, em certo sentido, a natureza para o animal. Em termos biológicos este nascimento equivale a um segundo nascimento, um nascimento que depende de cada um, por meio do qual aparecemos perante os outros como somente 
nós o somos e podemos ser. Pois a pluralidade não é a mera convivência entre iguais, mas entre seres que são também únicos. A natalidade em questão, portanto, não é aquela que remete àquele nascimento físico-biológico que ocorre à revelia de nossa vontade e que temos em comum com os demais seres vivos, mas àquele que somente a nós pertence, por meio do qual adentramos no espaço exclusivamente humano. Em toda tentativa de planificação ou supressão dessa situação singular efetiva-se certa renúncia daquilo que compete ao nascimento em questão, já que o espaço a que este nascimento remete - o espaço público - não nos é dado como a vida biológica, embora seja passível de mortalidade.

H. Arendt remete a natalidade à tradicional palavra grega "archein", "começar, conduzir e, finalmente, governar" (ARENDT, 2014, p.221), ou seja, agir é iniciar, é imprimir movimento a alguma coisa, é começar. As reflexões acerca da natalidade estão fundamentadas na filosofia política grega - no conceito de arqué, princípio - e na filosofia política cristã de Santo Agostinho. Esta natalidade ou princípio não existe antes do ser humano, dizendo respeito ao fato único ou singular de sua existência no mundo. "E tal princípio, como ele, antes jamais existiu. Para que existisse, foi criado o homem, antes de quem não existiu nenhum" (AGOSTINHO, 1990, p. 88). Deus criou o ser humano para que tudo tivesse um começo. O começo simplesmente dado de existirem crianças ainda não corresponde à essência da educação porque, por exemplo, a criança ainda não se sente responsável pelo mundo comum, ainda não nasceu para o mundo que é, por excelência, o lugar da existência humana considerado como convivência. Por isso a criança ainda não compreende que sua ação desencadeia um conjunto de possibilidades novas que não existiam antes dela, que o mundo a convoca para ser uma iniciadora, que este mundo é uma conquista humana, não meramente natural.

Pelo nascimento os homens são impelidos a agir. O início que pertence ao ser humano "não é o início de algo, mas de alguém que é, ele próprio, um iniciador" (ARENDT, 2014, p.222). Começar algo novo pertence ao ser humano e à sua natureza de iniciador. Não se espera isso das coisas inseridas dentro do mundo.

“O novo sempre acontece em oposição à esmagadora possibilidade das leis estatísticas e à sua probabilidade que, para todos os fins práticos e cotidianos, equivale à certeza; assim, o novo sempre aparece na forma de um milagre. O fato de o homem ser capaz de agir significa que se pode esperar dele o inesperado, que ele é capaz de realizar o infinitamente improvável. E isso, mais uma vez, só é possível porque cada homem é único, de sorte que, a cada nascimento, vem ao mundo algo singularmente novo. 
Desse alguém que é único pode-se dizer verdadeiramente que antes dele não havia ninguém. Se a ação, como início, corresponde ao fato do nascimento, se é a efetivação da condição humana da natalidade, o discurso corresponde ao fato da distinção e é a efetivação da condição humana da pluralidade, isto é, do viver como um ser distinto e único entre iguais" (ARENDT, 2014, p.222-223).

Nenhum homem, em termos de possibilidade, pode arrancar de outro esta singularidade. Pode-se, é claro, ocultá-la, escondê-la, desvirtuá-la por meio de discursos diversos, onde a vida humana e suas mais íntimas exigências são diluídas nas querelas entre amigos e inimigos, prós e contras. Então, e somente então, a conversa se torna mera conversa ou apenas meio para se atingirem determinados fins.

Mas, de que forma a conquista de alguma clareza acerca da essência da educação pode nos ajudar?

\section{A ESCOLA PROGRESSIVA OU NOVA.}

O que segue tem apenas o objetivo de contextualizar as observações de H. Arendt acerca da educação na perspectiva do pragmatismo e da escola progressiva. Com isso, a nosso ver, não está em jogo nenhum desmerecimento dos pontos de vista assumidos por tais perspectivas. O que está em jogo são os limites ou o projeto de fundo levado a cabo e que não se torna imediatamente visível por motivo evidente: todo ponto de vista, tal como algum foco de luz, nos orienta e nos faz ver os objetos que lhe dizem respeito, mas ele mesmo permanece de difícil acesso.

O pragmatismo é de origem inglesa. Nos EUA, sobretudo John Dewey e Willian Kilpratick aplicaram estas ideias ao campo da educação seguidos, no Brasil, pelo pedagogo Anísio S. Teixeira, incentivador da escola nova, pública, integral, democrática, baseada na experiência e no ensino profissional e técnico. O ambiente social e histórico do surgimento desta filosofia é a revolução industrial inglesa e todas as suas consequências materiais e espirituais: o ambiente da fábrica, dos engenheiros, do materialismo, dos ideais burgueses de progresso e de confiança nos sucessos das ciências naturais, de formação da classe operária, do liberalismo e seus princípios de liberdade, igualdade e fraternidade, de estabilidade, segurança, abundância e consumo, de busca da felicidade para o maior número onde o que deve ser valorizado é a utilidade segundo a medida desse tempo. A escola nova também se ocupa da transformação operada na maneira de sentir e de pensar o mundo (Cf. SPENGLER, 1941, p. 20-21; Cf. ARANHA, 2006, p.223-239; Cf. TEIXEIRA, 2007, p. 94ss). Neste contexto não deve assustar a ideia de uma escola pensada como uma fábrica e de uma fábrica como uma escola (Cf. FLUSSER, 2007, p. 42-43). Assim, Anísio Teixeira fundamenta a nova 
escola nas transformações da atualidade: confiança na experimentação científica e em seus métodos que tornaram toda verdade transitória; o industrialismo que modificou a concepção de família, de sociedade e de ser humano deslocando para a escola problemas que a educação tradicional, focada na família de outro tempo, não teria condições de trabalhar; a tendência à democracia e sua conexão com o espírito da ciência moderna que, numa certa interpretação, desloca a noção de autoridade para o agente, no caso, o aluno, como aquele que aprende fazendo adaptandose, assim, a um mundo em constante mudança (Cf. TEIXEIRA, 2007, p. 40-49).

"Que enormes, pois, são as novas responsabilidades da escola: educar em vez de instruir; formar homens livres em vez de homens dóceis; preparar para um futuro incerto e desconhecido em vez de transmitir um passado fixo e claro; ensinar a viver com mais inteligência, com mais tolerância, mais finamente, mais nobremente e com maior felicidade, em vez de simplesmente ensinar dois ou três instrumentos de cultura e alguns manuaizinhos escolares...” (TEIXEIRA, 2007, p. 49).

Neste sentido fica clara a finalidade da educação:

"A necessidade, pois, de a escola tomar, em grande parte, a si, as funções da família e do meio social corresponde a uma verdadeira premência dos nossos tempos, se quisermos dar às nossas crianças a oportunidade de se adaptarem e se ajustarem à ordem social do nosso vertiginoso presente" (TEIXEIRA, 2007, p.47).

E sobre o ensino baseado na experiência e no aprender fazendo bem como na experiência científica moderna:

"O mais importante, no momento, é notar como o ato de aprender depende profundamente de uma situação real de experiência onde se possam praticar, tal qual na vida, as reações que devemos aprender e, não menos profundamente, do propósito em que estiver a pessoa de aprender essa ou aquela coisa" (TEIXEIRA, 2007, p. 51).

"Para a escola progressiva, as matérias são a própria vida, distribuída por "centros de interesse ou projetos". Estudo é o esforço para resolver um problema ou executar um projeto. Ensinar é guiar o aluno na sua atividade e dar-lhe os recursos que a experiência humana já obteve para lhe facilitar e economizar esforços" (TEIXEIRA, 2007, p. 54). 


\section{AMPLIANDO A COMPREENSÃO DE EDUCAÇÃO.}

Toda crise é sempre a oportunidade de voltarmos às coisas elas mesmas. No caso de uma crise na educação, a chance de novamente nos perguntarmos acerca da mesma, de ganharmos alguma clareza sobre sua essência e de visualizarmos o alcance efetivo das interpretações especializadas dela.

"Uma crise só se torna um desastre quando respondemos a ela com juízos préformados, isto é, com preconceitos. Uma atitude dessas não apenas aguça a crise como nos priva da experiência da realidade e da oportunidade por ela proporcionada à reflexão" (ARENDT, 2007, p.223).

Chamamos a atenção para alguns aspectos da filosofia pragmatista e de sua influência na educação progressiva ou nova. Pois bem, que observações gerais, mas sintonizadas com a interpretação de natalidade realizada acima, podemos fazer?

A crise remete a três pressupostos básicos, segundo a autora: a existência de um mundo da criança (ARENDT, 2007, p. 230-231); a existência de uma ciência do ensino em geral, a pedagogia, em oposição aos saberes característicos de cada disciplina a ser ministrada no ambiente escolar (ARENDT, 2007, p.231); a supervalorização de uma "teoria moderna acerca da aprendizagem", o pragmatismo, que aplicado ao ensino visa "substituir, na medida do possível, o aprendizado pelo fazer" (ARENDT, 2007, p.232). Observemos, brevemente, este último ponto. Em foco está a absolutização do processo educacional e não uma rasa crítica à aplicação dos princípios do pragmatismo à educação.

Que significa substituir, na medida do possível, o aprendizado pelo fazer? Acentua-se o processo, o aprendizado constante, o aprendizado que se realiza ou efetiva numa ação efetiva e pontual buscando o conhecimento como a solução desejada para e a partir de problemas práticos dados. Aquele papel tradicional que ocupava o professor e o "conhecimento" e que fundamentava sua autoridade deve ser relativizado. Estamos diante de uma perspectiva que se insere no projeto de uma educação segundo as necessidades impostas pelo advento da sociedade de massas, industrializada e em constante mudança. Ela submete os indivíduos a um aprendizado constante, a uma adaptabilidade infinita, segundo as necessidades do tempo presente. A ideia mais recente de que o trabalhador nunca está completamente pronto para o mercado, necessitando atualizar 
continuamente seus conhecimentos e habilidades práticas, comprova o aspecto visionário da perspectiva pragmatista levada a capo pela escola progressiva.

Semelhante perspectiva conduz o professor ao exercício constante do aprendizado, não se detendo em conteúdos petrificados (ARENDT, 2007, p.232), mas, demonstrando "constantemente como o saber é produzido" (ARENDT, 2007, p.232). A ocupação com o método - a exemplo do método científico baseado na experimentação - é essencial. Então, não ensinar conhecimentos já sedimentados, mas sim o "aprender a fazer", aprender habilidades ou competências que sejam úteis a determinados propósitos práticos.

Segundo a pensadora, o que se oculta neste enfoque "exagerado" do processo de aprendizagem é a "diluição", por assim dizer, de uma diferenciação fundamental, "entre brinquedo e trabalho, em favor do primeiro" (ARENDT, 2007, p.232). Que significa isso? Percebe-se que a dificuldade de aprender conteúdos reside no fato destes serem por demais complexos, distantes da realidade da criança e, portanto, artificiais, não correspondendo ao modo de ser da criança. Ao se tematizar o processo de aprendizagem - aprender e ensinar fazendo - pretende-se recuperar o aspecto lúdico e não traumático do conhecimento. Dessa forma, em tese, haveria uma emancipação da criança, onde ela se libertaria de seu estado de passividade e submissão ao conhecimento tradicional e ao professor.

Tendo presente o que dissemos acerca da essência da educação podemos ensaiar algumas observações.

Uma educação que se ocupe privilegiadamente com seus aspectos funcionais comete o equívoco de se compreender exclusivamente a partir de seus fins. Em termos pragmáticos, a pergunta pelo sentido ou pela totalidade de uma concepção filosófico-pedagógica pode ser irrelevante. Mas para um alargamento da questão torna-se imprescindível. O que se ganha teoricamente com isso? Uma ampliação daquela compreensão do espaço público exclusivamente humano, composto por seres únicos e uma compreensão do próprio pragmatismo conforme o exposto, entendimento este que, de certa foram, o aspecto prático do mesmo não nos pode fornecer.

Façamos uma pergunta estranha: A compreensão que a escola progressiva detém de si mesma é, ela mesma, algo de pragmático ou utilitarista? A compreensão que funda a necessidade de se focar os processos, os métodos, a experiência, é, ela mesma uma compreensão que se adquire via experiência, isto é, fazendo? Caso nossa resposta seja negativa, então estaremos diante da possibilidade de uma compreensão - e justamente de uma compreensão inauguradora - que não se adquire experimentando. A dinâmica utilitarista que a atravessa, que gerencia sua prática, que 
orienta sua teoria funcional, etc., distingue-se da totalidade de sua concepção porque esta mesma a justifica. Assim, levando em conta os aspectos práticos que fundamentam todo o aprendizado, faz sentido nos perguntarmos por um último e primeiro "para quê", uma pergunta se se dirige para um nível diverso daquele que o utilitarismo pode alcançar. De modo semelhante, podemos também indagar: Mas, por que o espírito prático e útil tornou-se tão evidente hoje? Ao se tornar tão evidente, não está ele mesmo se isentando de uma investigação como tudo o que, na história, tornou-se comum e sabido por toda gente? O que se visa no enfoque extensivo da praticidade? Ora, a satisfação das mais diversas necessidades, a resolução dos problemas, a aproximação entre a educação e a vida. Afinal, estudar conteúdos tradicionais e distantes das necessidades práticas dos alunos aliena-os em relação à vida, já que os estudantes não se compreendem como sujeitos e agentes do processo, isto é, não aprendem a fazer, mas apenas a repetir o que foi realizado e petrificado numa longa tradição. No entanto, por que o enfoque no afazer constante e prático bem como nos aspectos lúdicos do aprendizado - esta aproximação e supervalorização do mundo da criança - tornaria necessariamente os mesmos sujeitos emancipados para participar melhor das questões mundanas? As questões mundanas repetem estruturalmente problemas de ordem prática ou utilitarista? O espaço público pensado por H. Arendt não corresponde aos interesses utilitaristas. Ao contrário, quando o desejo destes cresce, sempre o faz em detrimento daquele.

Que significa, então, este "último para quê"? A que ele remete? Os aspectos funcionais, práticos, utilitaristas, que orientam a educação - e que são importantíssimos a nosso ver - remetem eles mesmos a quê?

Distinto dos animais, o ser humano não visa à simples satisfação de suas necessidades biológicas ou meramente naturais, mas visa ao bem-estar, a uma ideia de vida ou de sentido orientador de todas as práticas, algo que por si só não se aprende fazendo, mas é seu nascedouro. Trata-se de algo que, em seu aspecto extremo, se mostra como "desneces sário" e que não se pode descobrir simplesmente pela mera prática. O aprendizado acerca deste último "para quê" não se dá como o resultado de algum afazer, mas como uma mudança abrupta de compreensão. Pois não é de ordem prática. O utilitarismo colabora mais para inserir o jovem nas tendências da sociedade de massas e de seus projetos coletivos do que emancipá-lo para participar como igual, porque único, do mundo comum dos homens livres. A mera aposta nos aspectos processuais e lúdicos do aprendizado dilui a adequada diferença e a boa distância para compreender o que se passa com a educação. Produz certo obscurantismo que, em termos políticos, oferece grandes vantagens. Não se pergunta ou se pensa de modo adequado o seguinte: que projeto de existência, de ser humano e de mundo, está em curso? 
A razão que orienta a concepção progressiva de educação não é, ela mesma, algo de prático submetido a alguma habilidade ou competência que se possa aprender ou ensinar desta forma. $\mathrm{O}$ afazer ali visado só se tornou necessário e fundamental à medida que ele se colocou a serviço de determinada ideia de humanidade, aquela que de tão evidente para nosso tempo continua não carecendo de questionamento. Mas, se não for posta em questão, como vê-la? Em que altura compreensiva nos colocamos para demandar tal visualização? Sem esta visualização a concepção pragmática de educação nada mais faz do que construir uma sociedade de autômatos "emancipados". "Portanto, para o homem somente é necessário o objetivamente supérfluo" (ORTEGA Y GASSET, 1965, p. 27). Esta necessidade de ordem não prática é inacessível pelos meios pragmáticos de ensino que frisam o processo e o aspecto lúdico. Porque estes a pressupõe. Pressupõe uma concepção de ser humano, de ensino, de sociedade. Afinal, não se pode, ontologicamente, eliminar o último "para quê", cuja resposta sempre remete a algum projeto essencial que, em última instância, responde à pergunta: viver, para quê? Educar, para quê?

Do ponto de vista político, fundado no discurso e na ação e no fato primordial de sermos iguais e diferentes, a fé no pragmatismo corresponde ao braço técnico de nosso tempo. Desse podemos esperar um ser humano melhor, mais evoluído? Ali a convivência humana corresponderá melhor à essência da educação, à natalidade? Para $\mathrm{H}$. Arendt a resposta é negativa pelo simples fato de que nestes procedimentos realiza-se o afastamento crescente do bom senso, da linguagem cotidiana, da possibilidade de nos discursos e atos entre iguais e diferentes os seres humanos poderem de fato iniciar uma nova cadeia imprevisível de eventos. No domínio da ciência estas características são abafadas e substituídas por algum ponto seguro e eficiente, capaz de levar o domínio da natureza para cada vez mais longe, para os confins do espaço, relativizando ainda mais o fato de que nascemos para o mundo. Ambiciona-se, assim nos parece, uma sociedade de funcionários, preparados ou programados segundo necessidades prévias deste quilate. A estatura humana ou a compreensão de ser humano que orienta as ações torna-se, assim, planificada, unidimensionalizada e, portanto, rebaixada. A conquista espacial não colaborou para o crescimento político do ser humano em sua humanidade, não elevou sua estatura mesmo indo cada vez mais para o alto, mas a diminuiu e pode destruí-la (Cf. ARENDT, 2007, p. 343-344).

\section{CONSIDERAÇÕES FINAIS.}

O aluno e o docente aprendem fazendo. Sem dúvida muito se aprende lidando com as coisas mais diversas. Aprende-se fazendo à medida que nos dispomos às características próprias daquilo que fazemos. $\mathrm{O}$ objeto nos orienta. Pelo menos se tivermos em vista a perspectiva artesanal. Mas o 
trabalho escolar, aquele aprendizado característico que pertence aos processos de ensino, não corresponde exatamente a este modelo. Há algo a mais a ser considerado. Podemos até - embora seja algo questionável - construir um paralelo com a ciência e seu caráter experimental que, inclusive, orienta a escola progressiva. Não significa isso que certa experiência de mundo, aquela da atualidade, precede toda compreensão de aprendizado, retirando do objeto - a educação - sua autonomia?

Por mais que foquemos a experiência no sentido já aludido é necessário que percebamos que nem tudo é da ordem da experiência e da experimentação. Por exemplo, as ideias de ciência, de objetividade, de subjetividade, de educação, etc., não são conhecimentos que se podem aprender fazendo porque, precisamente, orientam previamente todo a-se-fazer. Aprender algo por meio do exercício pertence à vida em graus e sentidos diversos. Mas não se pode aprender a educação desta forma, simplesmente porque ela não está submetida a esta espécie de experiência. Uma clareza mínima deste fenômeno a encontramos quando distinguimos o porquê da diferenciação entre o mestre e o aprendiz em qualquer habilidade e, no caso, entre o professor e o estudante. Foi também sempre um índice de sabedoria o conhecimento de certos princípios orientadores passíveis de ensino e de aprendizado, mas nunca obtidos pela mera prática. Seguindo nosso raciocínio, podemos dizer que também a liberdade e a democracia não são valores que se aprendem experimentando. Podemos sempre, é claro, exercitando-as, adentrar e compreender mais agudamente sua dinâmica. Mas isso também significa que já as acatamos em algum grau, que já estamos predispostos a estes sentidos dominantes. Igualmente as ideias de prática, de funcionalidade, de utilidade - slogans do pensamento utilitarista e/ou pragmatista. As ideias de praticidade, de funcionalidade ou de utilidade, enquanto evidências aceitas por nós, nunca são algo nascido meramente da experiência. Há uma diferença de sentido que a experiência, assim, não alcança, uma diferença de natureza, como se diz na filosofia tradicional. A escola nova defende a experiência como fundamental - e nós também mas a própria ideia de experiência tal como a modernidade a construiu com seu "método científico", não é experimentável desta maneira. Não se pode submeter a experiência a uma experimentação de mesmo nível. Teríamos que sondar o caráter teórico - não experimentável - da ciência moderna. A própria educação nunca é, ela mesma, fruto ou resultado da experiência. E, por fim, o que nos faz seres humanos nunca é resultado da experiência, nunca pode ser aprendido no exercício. O exercício pode sim nos despertar para esta situação de fundo, o que apenas confirma sua diferença. É porque já habitamos nesta situação ontológica de sermos seres humanos que podemos "ganhar" ou "perder" nossa humanidade. A experiência sempre pressuporá o ser que nos é próprio e que não possui o modo dos demais seres da natureza e das coisas. Tais raciocínios não 
desmerecem a experiência como o contínuo exercício em determinado afazer, buscando níveis cada vez mais elevados de maestria. Mas nem tudo está ao alcance desta compreensão de experiência. Faz-se necessário uma espécie de experiência de outra ordem ou outra sensibilidade intelectual. Visa-se uma tarefa de reconquista, propiciada por toda experiência de crise, do que é essencial e insubstituível e intransferível, daquele espaço de seres únicos que assim o são porque detêm no mais genuíno de seu ser a responsabilidade de serem iniciadores.

Terminando seu ensaio, afirma H. Arendt:

"O que nos diz respeito, e que não podemos portanto delegar à ciência específica da pedagogia, é a relação entre adultos e crianças em geral, ou, para colocá-lo em termos ainda mais gerais e exatos, nossa atitude face ao fato da natalidade: o fato de todos nós virmos ao mundo ao nascermos e de ser o mundo constantemente renovado mediante o nascimento. A educação é o ponto em que decidimos se amamos o mundo o bastante para assumirmos a responsabilidade por ele e, com tal gesto, salvá-lo da ruína que seria inevitável não fosse a renovação e a vinda dos novos e dos jovens. A educação é, também, onde decidimos se amamos nossas crianças o bastante para não expulsá-las de nosso mundo e abandoná-las a seus próprios recursos, e tampouco arrancar de suas mãos a oportunidade de empreender alguma coisa nova e imprevista para nós, preparando-as em vez disso com antecedência para a tarefa de renovar um mundo comum" (ARENDT, 2007, p.247).

\section{REFERÊNCIAS}

AGOSTINHO, Santo. A cidade de Deus. Parte II. Contra os pagãos. Petrópolis, RJ : Vozes, 1990.

ARANHA, Maria Lúcia de Arruda. Filosofia da Educação. São Paulo : Moderna, 2006.

ARENDT, Hannah. A condição humana. Rio de Janeiro : Forense Universitária, 2014. Entre o passado e o futuro. São Paulo : Perspectiva, 2007.

FLUSSER, Vilém. O mundo codificado. São Paulo : Cosac Naify, 2007.

ORTEGA Y GASSET, José. Meditación de la técnica. Madrid : Espasa-Calpe, S.A., 1965.

SPENGLER, Oswald. O homem e a técnica. Tradução de Erico Veríssimo. Porto Alegre : Edições Meridiano, 1941.

TEIXEIRA, Anísio. Pequena introdução à filosofia da educação. Rio de Janeiro : Editora UFRJ, 2007. 


\section{RESUMO:}

O texto pensa a educação e alguns aspectos de sua abordagem pragmatista a partir de uma compreensão do fenômeno da natalidade. No interesse de deixarmo-nos atingir pelas propostas de $\mathrm{H}$. Arendt organizamos o texto da seguinte maneira: iniciaremos dando uma resposta mínima (a) para o que a autora compreende por essência da educação, o fenômeno da natalidade; a partir destas ideias (b) faremos pequena incursão sobre a influência da filosofia pragmatista na educação que, no Brasil, tem em Anísio Teixeira seu maior expoente; por fim, teceremos (c) análise filosófica sobre o alcance desta compreensão para a educação. Com isso frisaremos a atualidade das observações da autora para nosso tempo.

Palavras-chave: natalidade, experiência, pragmatismo, ciência, Hanna Arendt.

\section{RESUMEN:}

El texto reflexiona sobre la educación y algunos aspectos de su enfoque pragmático a partir de una comprensión del fenómeno del nacimiento. Con el fin de dejarnos afectar por las propuestas de H. Arendt, organizamos el texto de la siguiente manera: comenzaremos dando una respuesta (a) a lo que el autor entiende por esencia de la educación, el fenómeno del nacimiento; a partir de estas ideas (b) haremos pequeña incursión en la influencia de la filosofía pragmática en la educación que, en Brasil, tiene en Anísio Teixeira su mayor exponente; (c) y al fin una análisis filosófico sobre el alcance de este entendimiento para la educación. Con esto enfatizaremos la relevancia de las observaciones del autor para nuestro tiempo.

Palabras clave: nacimiento, experiencia, pragmatismo, ciencia, Hanna Arendt.

\section{ABSTRACT:}

The text proposes to think about education and some aspects of its pragmatist approach from an understanding of birth's phenomenon. In the way of let ourselves be touched by $\mathrm{H}$. Arendt's ideas we organize the text as follows: we will begin by giving a minimal answer (a) to what the author understands by education's essence, that is, birth's phenomenon; from these ideas (b) we will make little foray into the influence of the pragmatist philosophy in education that, in Brazil, has in Anísio Teixeira its greatest exponent; and (c) a philosophical analysis on the scope of this understanding for education. With this we will emphasize the relevance of the author's observations for our time.

Keywords: birth, experience, pragmatism, science, Hanna Arendt.

Submetido em 30 de abril de 2019

Aprovado em 05 de agosto de 2019 